\title{
Electric Vehicles Participating in Frequency Control: Operating Islanded Systems with Large Penetration of Renewable Power Sources
}

\author{
P. M. Rocha Almeida, Student Member, IEEE, J. A. Peças Lopes, Senior Member, IEEE, F. J. Soares, \\ Student Member, IEEE and L. Seca
}

\begin{abstract}
This paper addresses the problematic of operating isolated networks with large penetration of intermittent renewable power sources, as well as the benefits that electric vehicles might bring to these systems. A small island's network was used as case study and a $\mathbf{1 0 0 \%}$ renewable dispatch for a valley period, only with hydro and wind generation, was tested in a dynamic simulation platform developed in Eurostag. Two distinct wind speed disturbances were simulated and, for both, the impact in the network's frequency was evaluated considering two different situations: electric vehicles only in charging mode and electric vehicles participating in primary frequency control. It was assumed the existence of $\mathbf{5 7 5}$ electric vehicles in the island. The impact of having electric vehicles performing primary frequency control in the expected batteries state of charge was also evaluated.
\end{abstract}

Index Terms-Electric Vehicles, Frequency Control, Isolated Systems, Renewable Energy Sources.

\section{INTRODUCTION}

$\mathrm{E}$ LECTRIC vehicles (EV) integration in islanded systems can be either a threat or a great opportunity for the power system operation. Some studies show the impacts that EV may have if integrated in the power systems as conventional loads, $[1,2]$, providing tools to identify and quantify those impacts. The main conclusion of these researches is that some controllability degree must be introduced to the EV charging process as many of the problems that arise from EV integration may be prevented.

In $[3,4]$ advanced control strategies are presented enabling a better usage of existing grid resources, postponing investments in grid reinforcement. The work presented in [5] describes the methodological approach to model EV connections to the grid, while regular loads and as primary frequency control providers.

However, this usage of EV resources available in the grid

This work was supported in part by Fundação para a Ciência e Tecnologia under SFRH/BD/48491/2008 and SFRH/BD/47973/2008 grants and within the framework of the Project "Green Island" with the Reference MIT-PT/SESGI/0008/2008, by Fundo de Apoio à Inovação (Ministério da Economia, da Inovação e do Desenvolvimento), within the framework of the Project REIVE - Redes Eléctricas Inteligentes com Veículos Eléctricos, and by the European Commission within the framework of the European Project MERGE - Mobile Energy Resources in Grids of Electricity, contract nr.241399 (FP7).

The authors are with INESC Porto, Faculty of Engineering, Universidade do Porto, R. Dr. Roberto Frias, 378, 4200-465 Porto, Portugal (e-mails: pedro.r.almeida@inescporto.pt, jpl@fe.up.pt, fsoares@inescporto.pt and lseca@inescporto.pt). must consist on a synergetic pathway for both EV owners and system operators. In [6-8] some solutions are presented in terms of possible regulation schemes or business model that would guarantee the adherence of EV owners to these advanced management strategies [9]. A survey about the economic and technical advantages of EV fleets for the power system can be found in [10].

Conceptual frameworks that allow taking advantage of the EV specific characteristics to improve the power system management are described in $[7,8]$.

The framework supported by [8] considers two layers of operation, normal and abnormal conditions. The first operates in a market environment, whereas the second halts market operation to enable fast actions by the system operator to assure that network technical restrictions are not violated. After the event that motivated the change is cleared EV owners get compensated for their availability.

This framework also distinguishes interconnected from isolated systems. Too often the latter do not operate in a market environment due to their dimensions. However, the need for advanced control techniques is still present and the fact that the grids of such systems are not very resilient demands for an efficient control structure. Islanded systems are then controlled by the system operator that is also responsible for compensating the EV owner's availability.

This work adopts the framework for isolated systems of [8] and implements the local control droop for EV described in [5], in order to use them to perform primary frequency control on a representation of the electricity grid of Flores, a small island of the Azorean archipelago. The representation of the island's distribution and generation systems is based on real data.

The case study evaluated is referred to a valley period with 575 EV plugged-in for charging purposes. All EV were assumed to be smart charging adherents [8], meaning that they act as controllable loads, being available to perform primary frequency control.

As the island has enough installed capacity to feed the system load with renewable energy sources (during valley periods), a $100 \%$ renewable dispatch was made and used in the case study addressed.

In order to evaluate if the provision of primary frequency control by EV impacts their charging in a significant manner, the simulation platform used was designed to perform two 
dynamic simulations: 1) over a short period of time (10 seconds) where a shortfall of $40 \%$ in the wind power is assumed and 2) over a larger period of time (1000 seconds), where fluctuations on wind power, due to wind speed intermittency, based on a real data series is considered. In the latter, the integral of the $\mathrm{EV}$ power contributions for the primary frequency control will be calculated to evaluate if the expected EV State of Charge (SoC) in the end of the simulation is influenced or not by the EV contributions to control the frequency.

In section II it is presented the case study addressed. The methodology used to perform the simulations, as well as the grid and EV modeling, are described in section III. The results for the single and the continuous disturbances are shown in section IV, while in section $\mathrm{V}$ are presented the main conclusions attained with the work developed.

\section{Methodology AND Modeling}

As it was explained in section I. this paper intends to evaluate the contribution of EV for frequency control of an isolated system.

Two stages were considered on the research. First, a single disturbance on Renewable Energy Sources (RES) power availability was simulated in order to illustrate a worst case scenario. Second, a chain of events was defined over a given period of time, consisting on RES resources fluctuations, based on real data for this case study.

To perform both stages of the work the methodology presented next was followed:

1. The isolated network dynamic model was characterized in terms of electricity grid and generation system.

2. With the defined disturbances, a dynamic simulation was conducted for the case where EV are regarded as simple loads.

3. The same simulation was conducted using EV to perform frequency control.

The obtained results allow analyzing the power system reaction in terms of frequency, the dispatched conventional units power and torque and the EV load.

\section{A. Grid Modeling}

The isolated network power system was modeled using the simulation software Eurostag.

A complete representation of the MV distribution network was made, including the step-up transformers from the existing generation units.

In terms of generation system, for the hydro turbines a conventional model with transient droop compensation was adopted from [11] coupled to a synchronous generator. The wind turbines were modeled as a controllable active and reactive power source, using a first-order model representing a spinning mass connected to a voltage-source converter that presents controllable electrical torque as presented in [12].

\section{B. EV Modeling}

Regarding the dynamic simulation model for EV, these were first considered to be regular loads (EV - charge mode) and in a second stage controllable loads (EV - frequency control) modeled as described in [5].

To manage EV as controllable loads a droop control law was adopted, Fig. 1. Each EV participating in frequency control will change its operation point by its nominal power for a deviation of $1 \mathrm{~Hz}$.

In the extreme situations an $\mathrm{EV}$ can reduce its load to $0.2 \mathrm{C}$ or increase the load to its rated power, $1 \mathrm{C}$. It was considered that $\mathrm{EV}$ in normal operation charge at $0.8 \mathrm{C}$. In order to prevent battery premature exhaustion and to avoid the usage of $\mathrm{EV}$ in the control of minor events, a dead band of $0.2 \mathrm{~Hz}$ was included.

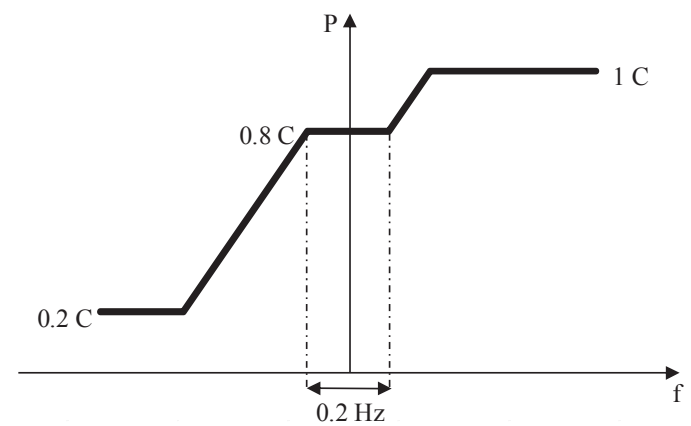

Fig. 1. Droop control for EVs.

Fig. 2 presents a simplified block diagram of the implementation of the described droop control for EV active power in Eurostag environment. Regarding reactive power, it was assumed that the EV power electronics interface with the grid is able maintain it constant with null value.

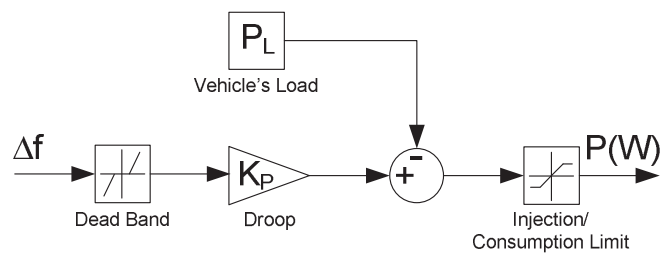

Fig. 2. Control loop for EVs active power set-point.

\section{CASE STUDY}

The island of Flores has a $15 \mathrm{kV}$ distribution network with a peak load of $3500 \mathrm{~kW}$ and a valley of $750 \mathrm{~kW}$, Fig. 3 .

The generation system is composed by four diesel generators with the nominal power of $625 \mathrm{kVA}$, two wind turbines of $330 \mathrm{kVA}$ and four hydro units, three of $370 \mathrm{kVA}$ and one with $740 \mathrm{kVA}$. All hydro turbines are installed in the same reservoir with a head height and length of the conduit of $106 \mathrm{~m}$ and $260 \mathrm{~m}$, respectively.

For the studied case a valley hour was chosen and so EV load was added to the conventional load. To attain the load from $\mathrm{EV}$ it was considered that $25 \%$ of the island's vehicle fleet (2300 vehicles) was replaced with EV and all of them were smart charging adherents, as defined in [3].

The EV fleet considered was composed by three vehicle types, $20 \%$ of which with $1.5 \mathrm{~kW}$ of rated power for battery 
charging, $40 \%$ with $3 \mathrm{~kW}$ and $40 \%$ with $6 \mathrm{~kW}$. A full charge cycle of $4 \mathrm{~h}$ was assumed for all the EV.

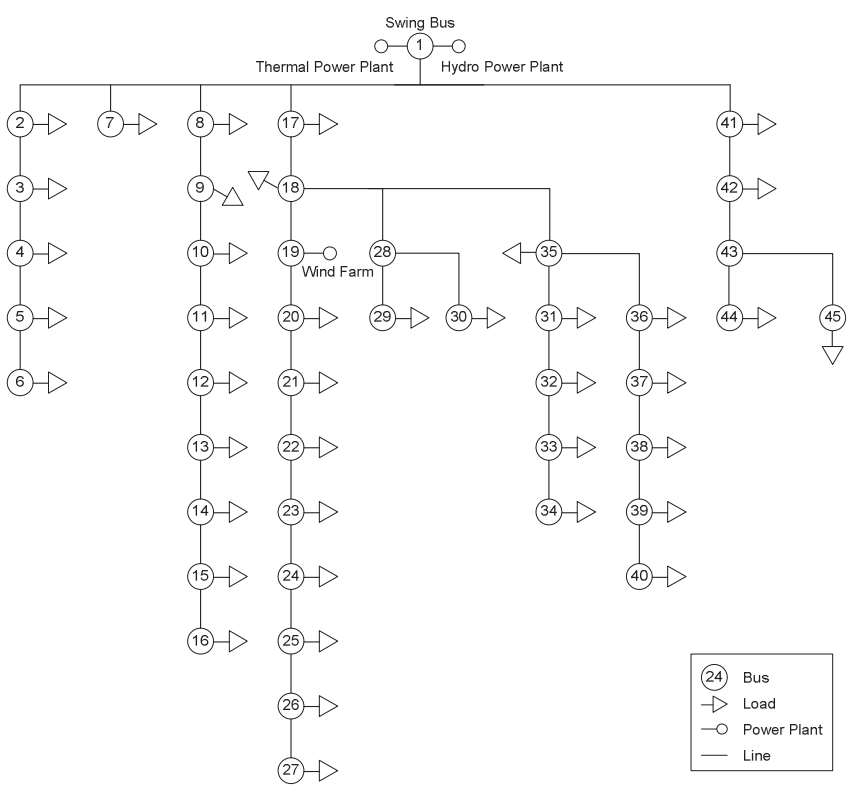

Fig. 3. Flores island distribution network

$\mathrm{EV}$ are assumed to be distributed through the network residential buses, proportionally to the active power installed on each bus. To each EV a battery State of Charge (SoC) was estimated using a Gaussian distribution function with an average value of $85 \%$ and a standard deviation of $20 \%$, with a range of allowable SoC between 0 and $100 \%$. All vehicles whose $\mathrm{SoC}$ was lower than $100 \%$ were charging at $0.8 \mathrm{C}$ and available to perform frequency control by changing the charging rate on the interval of $[0.2 \mathrm{C} ; 1.0 \mathrm{C}]$. As presented in Table I, this charging rate variation allows changing the EV aggregated power consumption from $962 \mathrm{~kW}$ to any value in the interval between $250 \mathrm{~kW}$ and $1200 \mathrm{~kW}$.

TABLE I

EV FleEt Characterization In the VALLey PeRiod ANALyZed

$$
\text { N. }{ }^{\circ} \text { of EV } 575
$$

$\mathrm{Nr}$. of EV with charging power of $1.5 \mathrm{~kW}$

115

Nr. of EV with charging power of $3 \mathrm{~kW}$

$\mathrm{Nr}$. of EV with charging power of $6 \mathrm{~kW}$

230

$\mathrm{Nr}$. of EV charging at $0.8 \mathrm{C}$

302

EV load at $0.8 \mathrm{C}(\mathrm{kW})$

962

EV maximum power consumption at $1.0 \mathrm{C}(\mathrm{kW})$

1200

$\mathrm{EV}$ maximum power consumption at $0.2 \mathrm{C}(\mathrm{kW})$

250

As the island has enough installed capacity to feed the system load with renewable energy sources, a fully renewable dispatch was made, using all the hydro units (assuming that favorable hydrological conditions exist) plus the two wind turbines producing $250 \mathrm{~kW}$ each. The detailed dispatch is presented in Table II.
TABLE II

\begin{tabular}{cccc}
$100 \%$ RENEWABLE DISPATCH FOR THE VALLEY PERIOD ANALYZED \\
\hline $\begin{array}{c}\text { Generation } \\
\text { Unit }\end{array}$ & $\begin{array}{c}\mathrm{S}_{\mathrm{n}} \\
\text { (MVA) }\end{array}$ & $\begin{array}{c}\mathrm{P}_{\mathrm{n}} \\
(\mathrm{MW})\end{array}$ & $\begin{array}{c}\mathrm{P}_{\text {Dispatch }} \\
(\mathrm{MW})\end{array}$ \\
\hline Hydro 1 & 0.37 & 0.33 & 0.3 \\
Hydro 2 & 0.37 & 0.33 & 0.3 \\
Hydro 3 & 0.37 & 0.33 & 0.3 \\
Hydro 4 & 0.74 & 0.64 & ref \\
\hline
\end{tabular}

Aiming at the evaluation of the dispatch robustness to wind power fluctuations, two scenarios of wind power variations were studied:

1) Single disturbance - a sudden shortfall of $40 \%$ in the generated power was simulated over 10 seconds; the wind farm power output is presented in Fig. 4;

2) Continuous disturbances - an intermittent wind speed behavior, based on a real data series, was simulated over 1000 seconds; the respective wind farm power output is presented in Fig. 5;

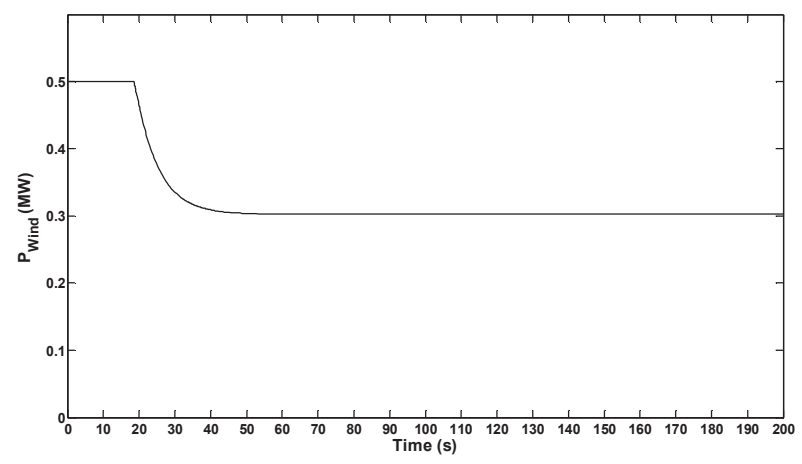

Fig. 4. Wind farm power output during the single disturbance simulation

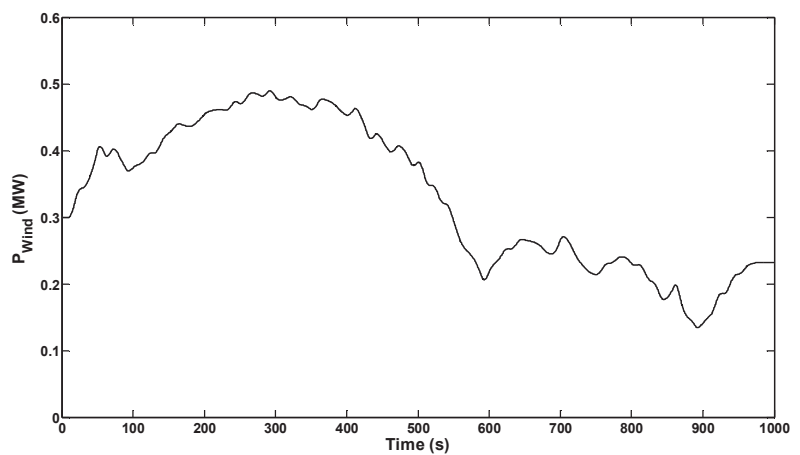

Fig. 5. Wind farm power output during the continuous disturbances simulation

All the simulations were performed using the dynamic simulation software Eurostag.

\section{RESULTS}

\section{A. Single Disturbance}

Fig. 6 shows the system frequency when the shortfall on wind presented in Fig. 4 occurs. In typical operating conditions frequency would drop to $48.2 \mathrm{~Hz}$, whereas when EV participate in frequency control frequency would only drop to $49.7 \mathrm{~Hz}$. The EV fast reaction to the disturbance 
contributed significantly to the frequency oscillations damping that was verified when EV were performing primary frequency control.

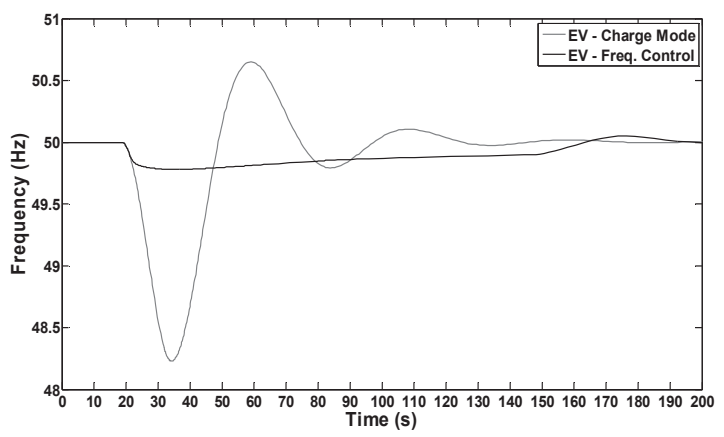

Fig. 6. System frequency during the wind power shortfall

Fig. 7 and 8 show, respectively, the mechanical and electrical torque evolution on the largest hydro unit, for $\mathrm{EV}$ only in charging mode and EV participating in primary frequency control.

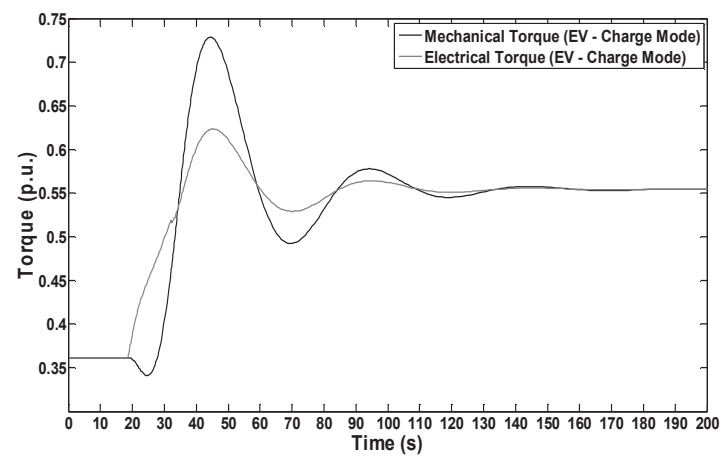

Fig. 7. Electrical and mechanical torque of hydro unit 4 when EV are modeled as uncontrollable loads

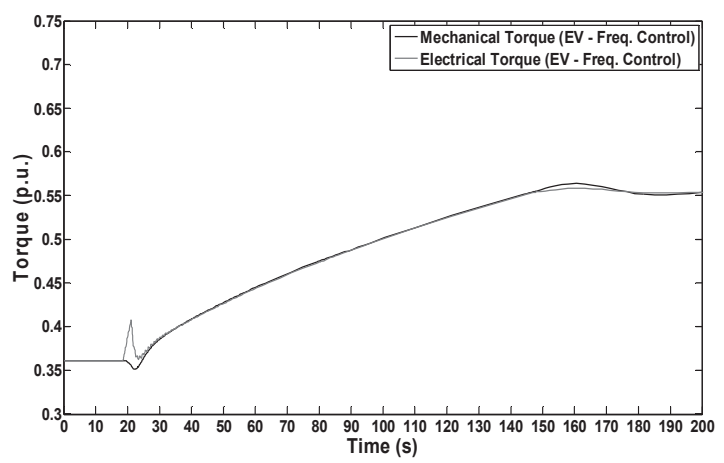

Fig. 8. Electrical and mechanical torque of hydro unit 4 when EV participate in primary frequency control

Conversely, when EV participate in primary frequency control, the electrical and the mechanical torque have a close evolution as the EV allow a slower response from the hydro units. In this mode of operation, the initial response is the same as when EV are modeled as uncontrollable loads, as Fig. 9 depicts. This situation occurs due to the existence of a dead band (see Fig. 4) where EV do not react to small frequency deviations. When EV start decreasing their power consumption, then the lag between mechanical and electrical torques disappears.

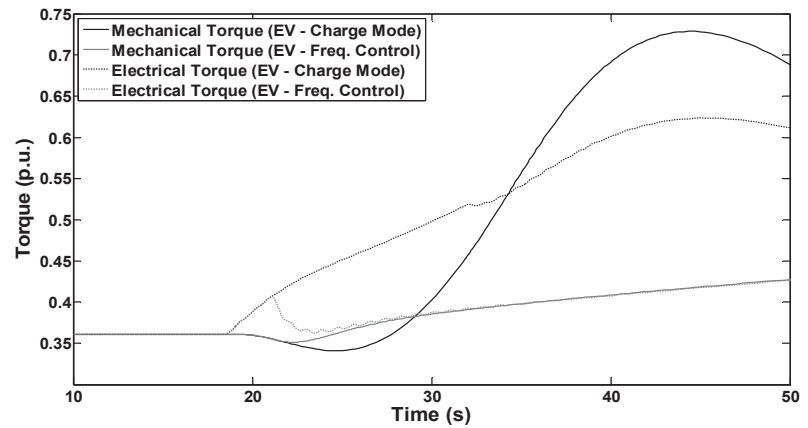

Fig. 9. Torque on the initial moments after the disturbance in both modes of operation: uncontrollable loads and performing primary frequency control

Fig. 10 presents the active power consumption of EV aggregated in buses 25 and 33 of the network, in both modes of operation. The EV have a very quick reaction to frequency deviations and return to their original consumption value once the system is stabilized, since they do not possess an integral control loop.

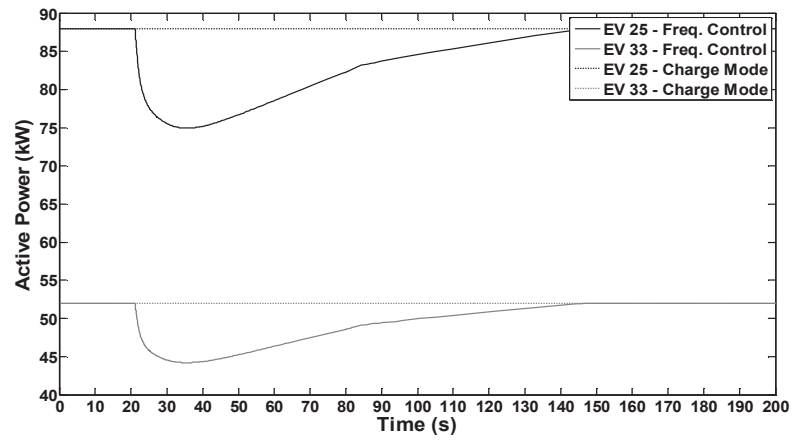

Fig. 10. Aggregated active power consumption of all the EV connected in the network buses nr. 25 and 33

\section{B. Continuous Disturbances}

Fig. 11 presents the evolution of frequency along the simulation. When EV do not participate in primary control, the system frequency depends entirely in the existing hydro units that compose the dispatch in this period.

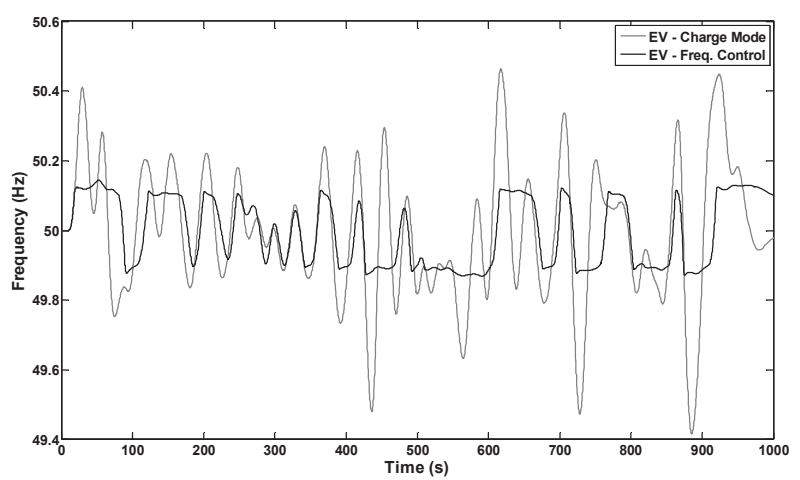

Fig. 11. Frequency evolution for continuous disturbances simulation. 

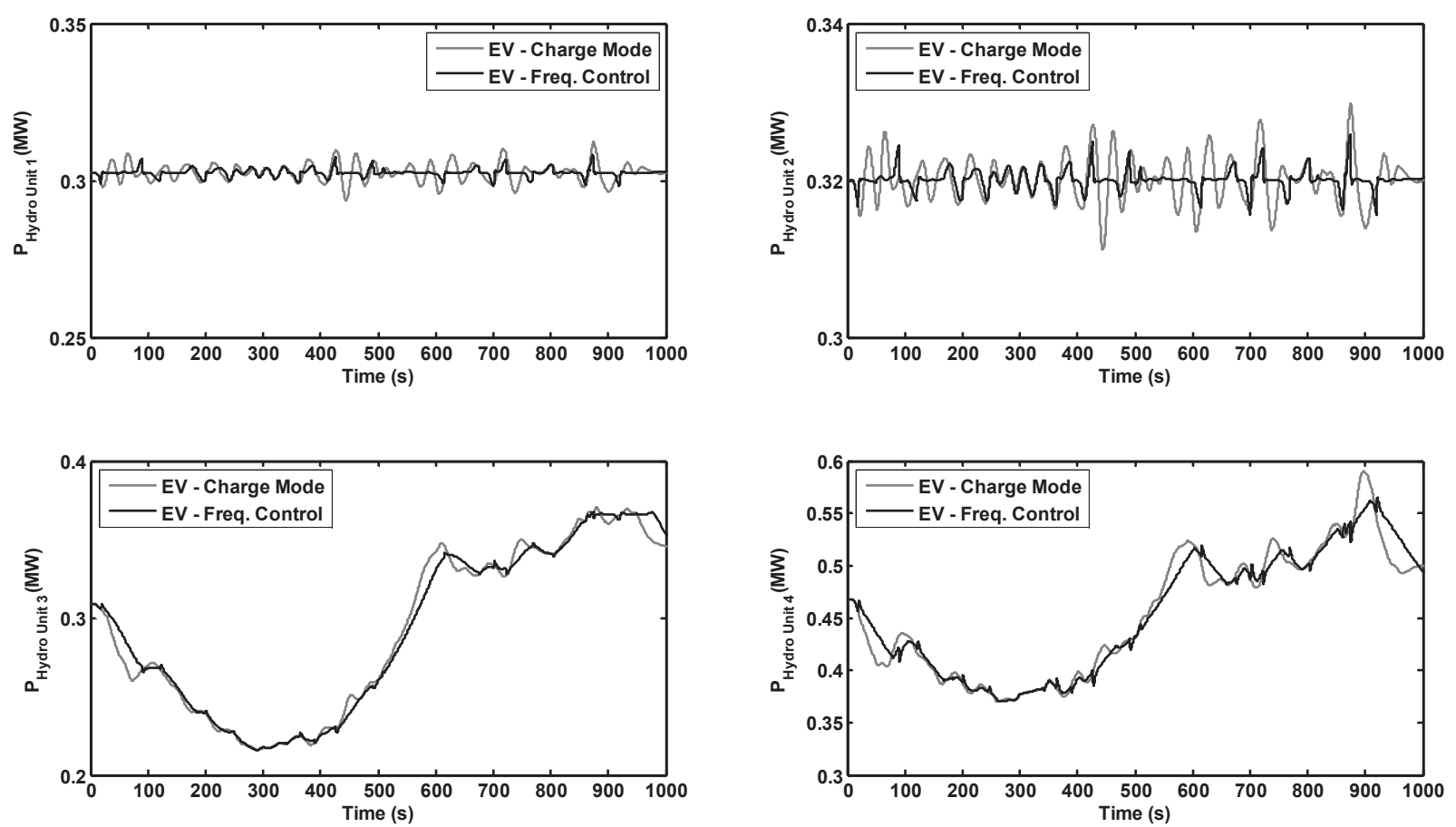

Fig. 12. Active power of the hydro units for continuous disturbances simulation.

Thus, frequency oscillates in a band of approximately 49.4 $\mathrm{Hz}$ and $50.4 \mathrm{~Hz}$. Using EV as controllable loads enable a much smoother frequency response, straightening the oscillation band from $1 \mathrm{~Hz}$ to roughly $0.3 \mathrm{~Hz}$. The effect of the dead band imposed to the EV controller is noticeable in the figure, as the system frequency with EV control is similar to the EV charge mode case for low deviations of frequency.

Fig. 12 depicts the active power of the dispatched generation units. Being controlled with constant torque, the hydro units 1 and 2 maintain their production level constant.

The small fluctuations that are observable are part of the natural response of the synchronous generators. Regarding hydro unit 3 , this machine follows the wind power fluctuations reaching for $\mathrm{t}>850 \mathrm{~s}$ it maximum output power, in both studied cases. Hydro unit 4 reaction is analogous to unit 3, but as it has greater nominal power this unit does not reach a saturation level. For all the generation units, when EV control is active ramping is much smoother, avoiding sudden changes that if continued may be lead to premature fatigue of the mechanical parts of the hydro units.

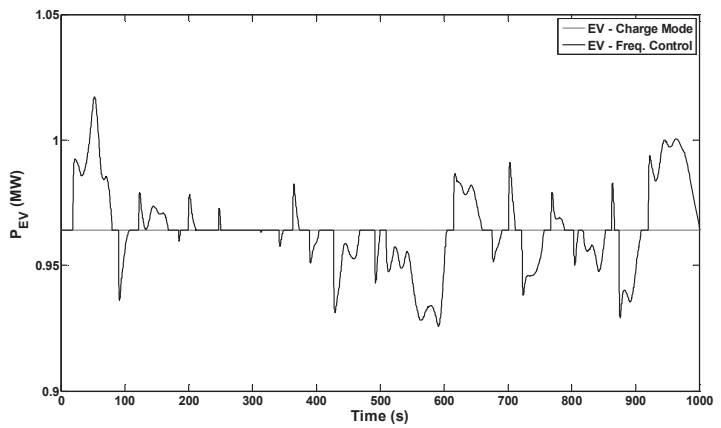

Fig. 13. Active power load of the EV for continuous disturbances simulation.
Regarding the EV, the evolution of their load is shown in Fig. 13. As it can be perceived (by analyzing both this figure and figure 11) the EV change their operation state very fast, with just a slight delay in relation to the load / generation imbalance and for frequency deviations larger than the specified dead band. The largest contribution from EV represented a change of only $5.7 \%$ of their total power consumption.

\section{Impact of Primary Frequency Control Provision in the Expected Battery SoC}

To evaluate possible impacts that may affect SoC during the provision of primary control, the amount of energy consumed by EV was calculated, for the studied scenarios. During the $1000 \mathrm{~s}$ period, if EV are regarded as simple loads then they would consume $267.8 \mathrm{kWh}$, whereas with EV control the consumed energy would be $268.0 \mathrm{kWh}$. In this case primary frequency control would lead to a deviation of $0.08 \%$ of the total required energy.

\section{CONCLUSIONS}

With the development of this work it was possible understand how using EV to provide primary frequency control impacts not only the power system but also the SoC of the EV batteries.

In the case of the island of Flores there is a lot of unexplored RES availability as the system load is low and typical dispatching rules must always include conventional generation units for stability purposes. Moreover, the existing hydro units would not be included in frequency control actions as the high head and the long conduit would cause premature mechanical wear and tear. The usage of EV to perform fast control actions proved efficient and enabled the usage of the 
hydro units in load / generation balancing. As EV have a faster reaction the ramping of hydro units is smoother and requests for sudden changes seldom occur.

With EV control the system frequency oscillated in turn of $50 \mathrm{~Hz}$ in a band of $0.3 \mathrm{~Hz}$, whereas if hydro units alone would be used to perform this control frequency would oscillate in a $1 \mathrm{~Hz}$ band.

$\mathrm{EV}$ charging process was almost not affected as the amount of consumed energy deviated from the expected value by 0.08 $\%$.

Future studies may focus on the possibility of having different adherence rates to smart charging schemes in order to verify the need for a specific regulatory framework for isolated systems. The inclusion of EV load forecasting behavior and operation procedures, within a Morecare like system [13], may even promote a better management of the water in the hydro reservoir and prolong the periods where a full renewable dispatch may be performed.

The achieved results indicate that knowing the expected battery $\mathrm{SoC}$ is a matter that should be further investigated, as well as EV battery degradation due to the provision of this type of services.

\section{ACKNOWLEDGEMENTS}

The work presented in this paper was developed within the framework of the doctoral MIT Portugal program activities.

\section{REFERENCES}

[1] F. J. Soares, J. A. Peças Lopes, P. M. Rocha Almeida, "A Monte Carlo Method to Evaluate Electric Vehicles Impacts in Distribution Networks", 2010 IEEE Conference on Innovative Technologies for an Efficient and Reliable Electricity Supply, Boston, USA, September, 2010.

[2] Clement-Nyns, K.; Haesen, E.; Driesen, J., "The Impact of Charging Plug-In Hybrid Electric Vehicles on a Residential Distribution Grid," IEEE Transactions on Power Systems, vol.25, no.1, pp.371-380, February, 2010.

[3] J. A. Peças Lopes, F. J. Soares, P. M. Rocha Almeida, "Identifying Management Procedures to Deal with Connection of Electric Vehicles in the Grid", PowerTech2009 - PowerTech 2009, Bucharest, Romania, June, 2009

[4] M. D. Galus, G. Andersson, "Demand Management of Grid Connected Plug-in Hybrid Electric Vehicles", IEEE Energy2030 Conference, November, 2008.

[5] J. A. Peças Lopes, P. M. Rocha Almeida, F. J. Soares, "Using Vehicleto-Grid to Maximize the Integration of Intermittent Renewable Energy Resources in Islanded Electric Grids", ICCEP 2009 - International Conference On Clean Electrical Power Renewable Energy Resources Impact, Capri, Italy, June, 2009.

[6] W. Kempton, S. Letendre, "Electric Vehicles as a New Power Source for Electric Utilities", Transportation Research Part D: Transports and Environment, 1997.

[7] C. Guille, G. Gross, "A Conceptual Framework for the Vehicle-to-grid (V2G) Implementation”, Energy Policy 2009, 37, 4379-4390, November, 2009.

[8] J. A. Peças Lopes, F. J. Soares, P. M. Rocha Almeida, "Integration of Electric Vehicles in the Electric Power System", Proceedings of the IEEE, accepted for publication.

[9] R. J. Bessa, M. A. Matos, "The role of an aggregator agent for EV in the electricity market," in Proceedings of the 7th Mediterranean Conference and Exhibition on Power Generation, Transmission, Distribution and Energy Conversion, Agia Napa, Cyprus, 7-10 Nov. 2010.

[10] R. J. Bessa, M. A. Matos, "Economic and technical management of an aggregation agent for electric vehicles: a literature survey," European Transactions on Electrical Power, 2011, In Press. DOI: 10.1002/etep.565.
[11] P. Kundur, "Power System Stability and Control", McGraw-Hill Inc., New York, 1994.

[12] J.G. Slootweg, S.W. de Haan, H. Polinder, W.L. Kling, “Aggregated Modelling of Wind Parks with Variable Speed Wind Turbines in Power System Dynamics Simulations", In: Conf. Proc. of the 14th Power Systems Computation Conference (PSCC), Sevilla, Spain, June 24-28 2005.

[13] J. A. Peças Lopes, N. Hatziargyriou, M. H. Vasconcelos, J. N. Fidalgo, E. Karapidakis, "Dynamic Security Evaluation Functions in the Morecare Project", Proceedings of MedPower2002 - 3rd Mediterranean Conference and Exhibition on Power Generation, Transmission, Distribution and Energy Conversion, Athens, Greece, November, 2002.

\section{BIOGRAPHIES}

P. M. Rocha Almeida (S'09) received the Electrical Engineering degree (five-year course) in 2007 from the Faculty of Engineering, Porto University, Porto, Portugal. He is currently pursuing a Ph.D degree from the MIT Portugal Program on Sustainable Energy Systems, Faculty of Engineering, University of Porto, Porto, Portugal.

$\mathrm{He}$ is a Researcher in the Power Systems Unit of INESC Porto. His main research interests are focused on power systems dynamics, control and electric vehicle integration.

J. A. Peças Lopes (M'80-SM'94) received the electrical engineering degree and the Ph.D. degree in electrical engineering from the University of Porto, Porto, Portugal, in 1981 and 1988, respectively. In 1996, he received the Aggregation degree from the University of Porto.

$\mathrm{He}$ is Full Professor in the Department of Electrical Engineering of the Faculty of Engineering of University of Porto and Director of the Sustainable Energy Systems PhD course. He is also Director of Instituto de Engenharia de Sistemas e Computadores do Porto (INESC Porto).

F. J. Soares (S'09) received the Physics degree (five-year course) in 2004 from the Faculty of Sciences and an Electrical Engineering (Renewable Energies) Post-Grad in 2007, both in Porto University, Porto, Portugal. He is currently pursuing a Ph.D degree from the MIT Portugal Program on Sustainable Energy Systems, Faculty of Engineering, University of Porto, Porto, Portugal.

He is a Researcher in the Power Systems Unit of INESC Porto. His main research interests are focused on the assessment of electric vehicles impacts on the power systems.

L. Seca received a degree (5-year course) and an M.Sc. (2-year course), both in Electrical Engineering, from FEUP, Portugal in 2002 and 2006, respectively. He is currently a researcher/consultant in the Power Systems Unit of INESC Porto.

His current research interests include steady state and dynamic studies on integration of distributed energy resources in transmission and distribution networks, voltage and frequency control and ancillary services provision. 